Capacitive Discharge Firing System for Providing Acoustic Sources in the Hot Dry Rock Geothermal Energy Development Project

¿

$\frac{7}{\omega}$

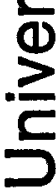




\section{DISCLAIMER}

This report was prepared as an account of work sponsored by an agency of the United States Government. Neither the United States Government nor any agency Thereof, nor any of their employees, makes any warranty, express or implied, or assumes any legal liability or responsibility for the accuracy, completeness, or usefulness of any information, apparatus, product, or process disclosed, or represents that its use would not infringe privately owned rights. Reference herein to any specific commercial product, process, or service by trade name, trademark, manufacturer, or otherwise does not necessarily constitute or imply its endorsement, recommendation, or favoring by the United States Government or any agency thereof. The views and opinions of authors expressed herein do not necessarily state or reflect those of the United States Government or any agency thereof. 


\section{DISCLAIMER}

Portions of this document may be illegible in electronic image products. Images are produced from the best available original document. 
This work was supported by the US Department of Energy, Division of Geothermal Energy. employees, nor any of their contructors, subcontractors, or their employees, makez any warranty, express or implied, or casumes any lezal liability or responsibility for the accuracy. completeness, or usefulness of any information. apparutus.

produce, or process disclosed, or represents that its use would
not infringe privately owned rishts. 
LA-7761-MS

Informal Report

UC-66c

Issued: July 1979

\title{
Capacitive Discharge Firing System for Providing Acoustic Sources in the Hot Dry Rock Geothermal Energy Development Project
}

\author{
William W. Patterson \\ David R. Deam * \\ Herbert J. MacDonald* \\ Richard H. Rochester
}

"Reynolds Industries, Inc., 3420 Fostoria Way, P.O. Box 214, San Ramon, CA 94583.

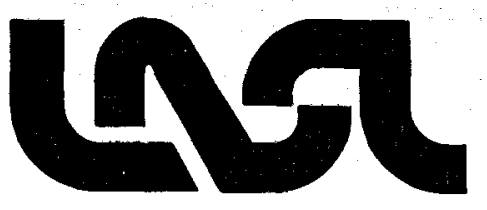

This epont was prepared as an eceount of work sponsored by the United States Government. Neither the United States nor the United States Department of Energ, nor any of their employees, nor any of their contractors, subcontracton, of their employees, anakes any warranty, express or implied, or anumes any kegal liability or responsibility for the accurncy, completeness or usefulness of any information, apparatus, product or process dieclosed, or represents that its use would not infringe privately owned rights. 
CAPACITIVE DISCHARGE FIRING SYSTEM FOR PROVIDING

ACOUSTIC SOURCES IN THE HOT DRY ROCK

GEOTHERMAL ENERGY DEVELOPMENT PROJECT

by

William W. Patterson, David R. Deam Herbert J. MacDonald, and Richard H. Rochester

\section{ABSTRACT}

This report describes the development of a capacitive discharge firing unit designed to initiate electrically exploded foil slapper detonators in a subsurface, high-pressure (5000 psi), high-temperature $\left(>200^{\circ} \mathrm{C}\right)$ environment. The unit is used to conduct acoustic ranging experiments in deep boreholes $(=10000 \mathrm{ft})$ in the Los Alamos Scientific Laboratory Geothermal Hot Dry Rock experiment.

\section{INTRODUCTION}

The Los Alamos Scientific Laboratory is conducting a program to demonstrate the feasibility of extracting energy from hot dry rock in the earth's crust. Heat extraction is based on a pressurized water circulation loop created by drilling two holes from the surface and connecting them by a large network of cracks produced by hydraulic fracturing. The capacitive discharge firing system described here was designed with a geophone package to determine hole location, fracture size, and fracture direction during long-term tests $\left(\approx 24\right.$ hours) downhole at $200^{\circ} \mathrm{C}$ and $31-41$ MPa $(5000-6000$ psi). The system is designed to operate over cable lengths of $25000 \mathrm{ft}$.

II. THE FIRING SYSTEM

The firing system consists of an uphole control unit, a downhole firing module, a detonator rack, and high-temperature detonators. Design features are as follows. 
a. An uphole control unit with encoder to select and fire up to 12 detonators.

b. Memory circuits and displays to monitor which of the 12 detonators have been fired.

c. A tubular 3-in-o.d. downhole firing module to operate through $25000 \mathrm{ft}$ of seven-conductor logging cable.

d. A high-temperature, electrically exploded foil slapper initiator, or detonator using hexanitrostilbene (HNS) explosive that is inherently safe from accidental detonation, vibration, shock, or transient electrical sources.

III. THE UPHOLE CONTROL UNIT

The $115-\mathrm{V}$ ac control unit is packaged in an 11 by 7 by 7 in. moisture-sealed carrying case (Fig. 1) with operating instructions printed inside the cover. On the front panel are the connectors that connect the unit to the firing module, to the ac power outlet, and to the monitoring instrumentation. The switches serve to keylock system power, select which detonator will be fired, and fire that detonator. Also on the front panel are status indicators that show when the system is armed, what detonators have been fired, and when firing is complete.

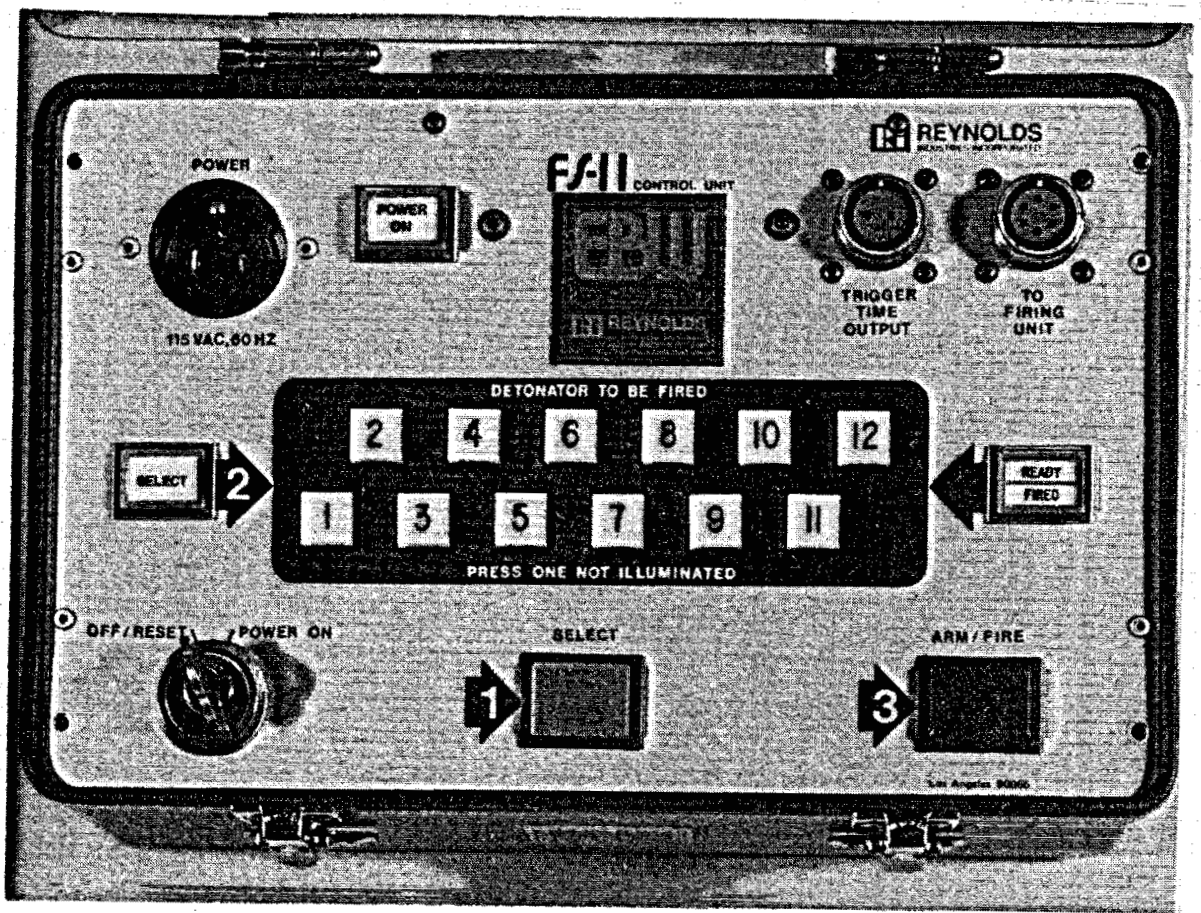

Fig. 1. Exterior view of the uphole control unit. 
Internally the control unit contains a U-shaped chassis that supports the large electrical components, a printed circuit (PC) "mother board," and six plug-in PC cards that mount most electronic components (Fig. 2).

A. The Printed Circuit Cards

The PC cards include an interface card that interconnects the front panel controls and connectors, a power supply card that establishes system power, and an "encoder" card that reduces from 14 to 6 the number of wires needed to connect the control unit to the downhole firing module. Two of the remaining PC cards are sixchannel program/memory cards that permit preselection of a particular detonator to be fired and store data as to which detonators have already been fired. The sixth card is the "control" card that buffers all front panel controls and provides the analog and logic control functions necessary for proper system operation. This card also contains circuitry that automatically compensates for variations in the type and length of the downhole cable used to connect the control unit to the firing module.

B. The circults cuits.

Figure 3 is a block diagram of the uphole control unit cir-

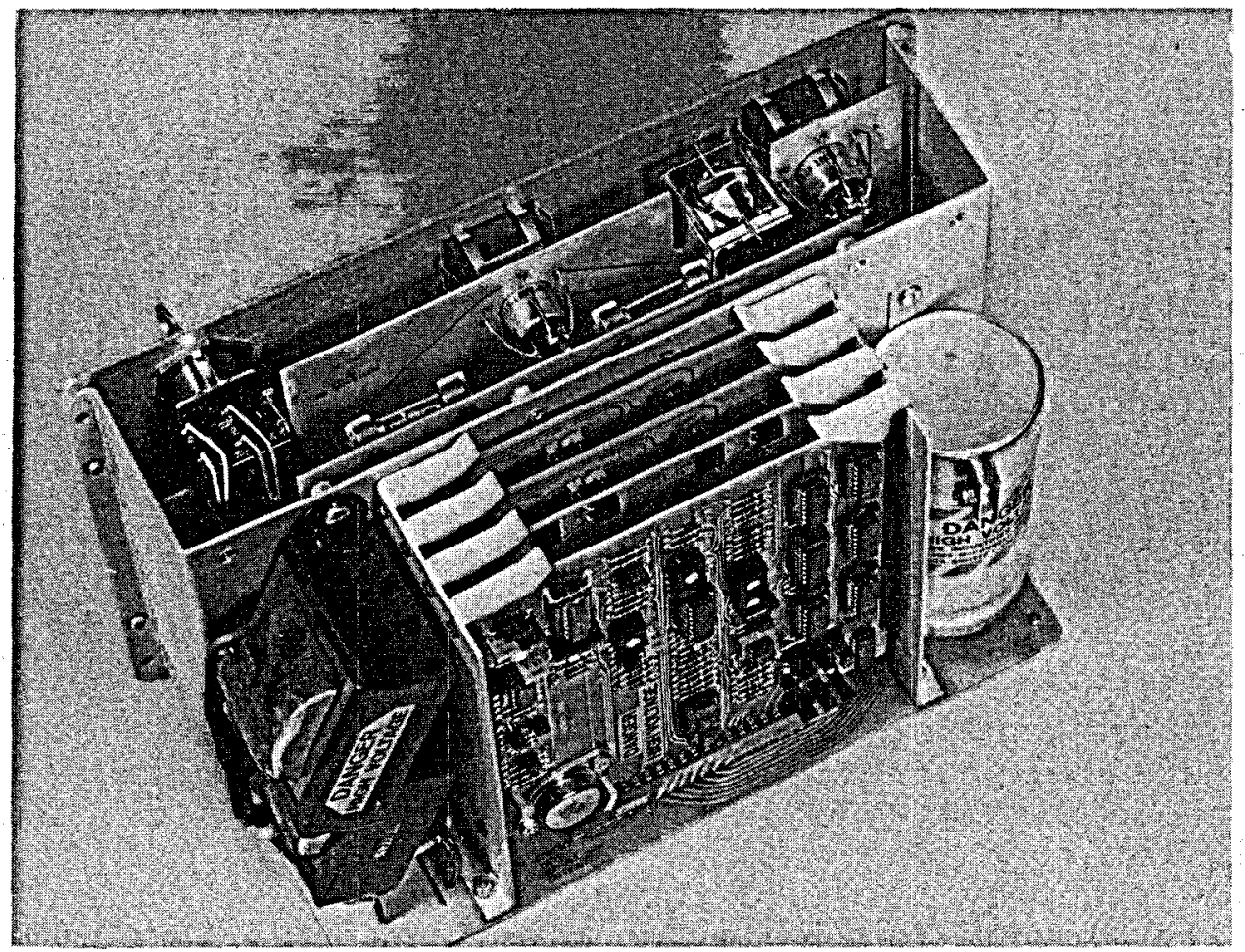

Fig. 2. Internal view of the uphole control unit. 


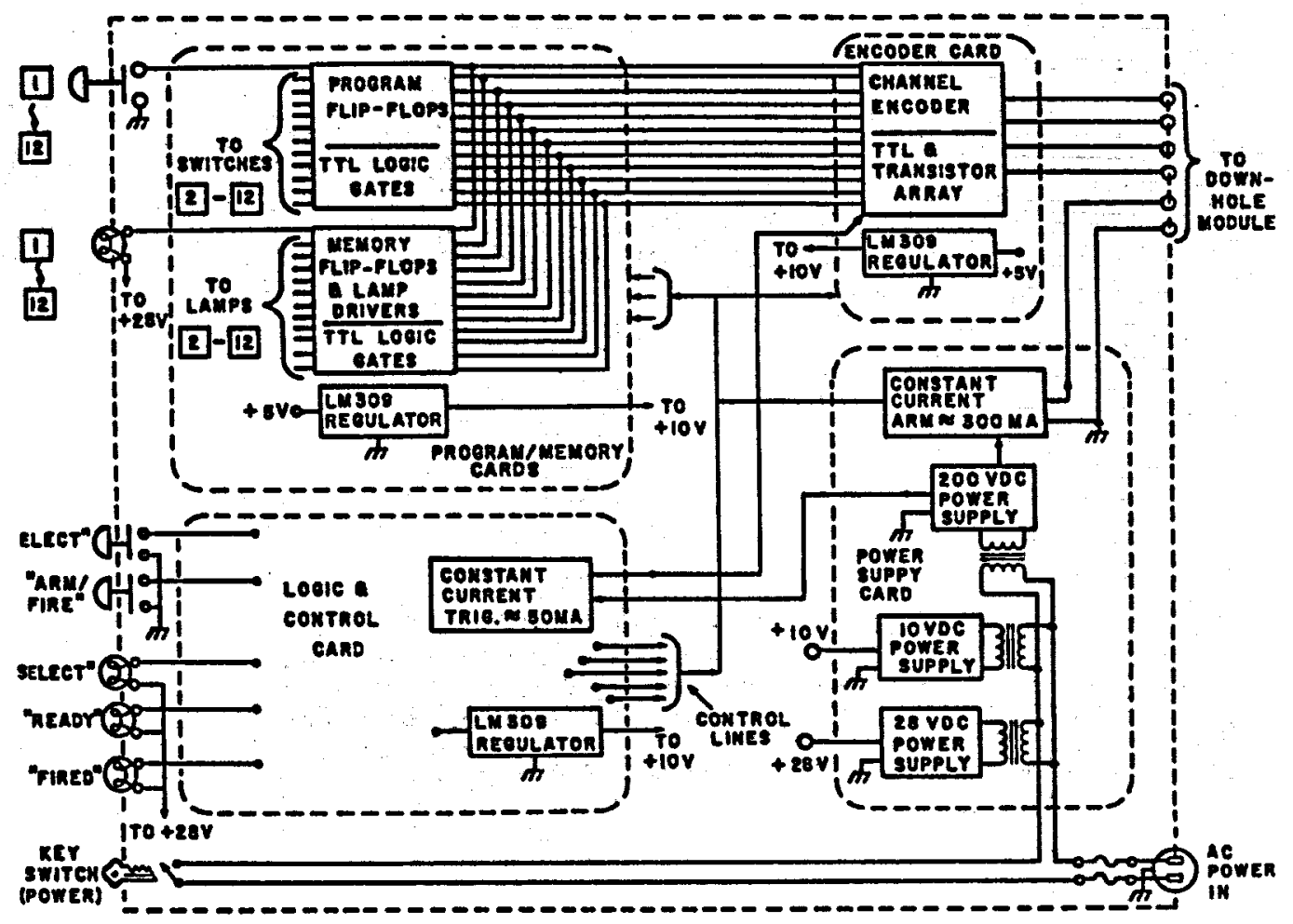

Fig. 3. The uphole control unit.

1. Power supplies. The control unit contains three main power supplies: $5-\mathrm{V}$ dc for control and logic circuitry, 28-V dc for indicator lamps, and $200-\mathrm{V}$ dc for arming and triggering the downhole firing module. Each supply is a basic full-wave transformer type. The $200-\mathrm{V}$ and $28-\mathrm{V}$ dc supplies use simple zener rectifiers to clamp the voltage at a maximum value to protect the filter capacitors. The $5-\mathrm{V}$ dc supply is an unregulated $10-\mathrm{V}$ dc supply that is distributed to the plug-in cards. These cards have their own IM309K, or H-type regulators for regulation to $5-\mathrm{V} d c$.

The 200-V dc supply is wired to two separate constant-current regulators, one for arm power $(\simeq 300 \mathrm{~mA})$ and the other for trigger power $(\approx 15 \mathrm{~mA})$. The constant-current regulators automatically set arm and trigger current to the downhole firing module at a fixed value. Because the current is held constant, accidental shorts to ground will not overload and damage components or even blow fuses. To guard against component damage from "hard" shorts, the unit has shut-down protection circuitry to abort arm/trigger power to the downhole firing module. These circuits are discussed in more detail later.

Each power supply is wired through resistors to separate poles of a normally closed, four-pole, double-throw (4PDT) relay that discharges all supplies and filter capacitors within 5 s after power is removed. 
2. Encoder Circuitry. The encoder card input is connected to the 12-channel select buss from the program/memory cards. The encoder card contains arrays of $74 \mathrm{LS}$-type TTL "NOR" and "OR" gates, optical couplers, and transistor circuits, all of which convert information about the selected detonator to one of the 12 possible combinations and polarities on two of four wires. This encoded information is sent to the downhole firing module when the control circuitry issues a trigger command.

3. Program/Memory Circuitry. This circuitry on the program/ memory cards (six channels per card), consists of 74LS-type TTL logic gates, flip-flops, and a lamp driver. The flip-flops serve as a memory to store data as to which detonator has been selected to be fired (program) as well as storing information concerning which detonators have been fired. The 12-program flip-flop outputs are tied to the channel-select buss that goes to the encoder card. The 12-memory flip-flop outputs are tied to the lamp drivers that drive front-panel display lamps to indicate which detonators have been fired. This is controlled by the control circuitry.

4. Control Circuitry. This circuitry monitors and regulates control unit operation and guards against overloads and improper front panel operation. It is located on the control card, which is the outer-most plug-in card, to allow easy adjustment of the various trim pots used for calibration. The more important circuits on the control card include arm and trigger timers, flasher, switch debounce, power-up reset, lamp drivers, constant-current circuits, protection, and logic circuitry. The following is a brief description of these circuits.

a. Arm and Trigger Timers. These timers establish the duration of the arming $(1-13 \mathrm{~s})$ and triggering ( $10 \mathrm{~ms})$. The timer circuits consist of a "556" dual-timer chip and various discrete components used to support it.

b. Flasher. This circuit "flags" the display and indicates which initiator is ready to be fired. It consists of a "555" timer chip and discrete components that determine the flashing rate.

c. Switch Debounce. This circuit eliminates the bouncing of the switch contacts from interfering with unit operation. It uses 74LS-type TTL NAND gates to fabricate a set-reset (SR) flip-flop.

d. Power-Up Reset. The power-up reset clears the flip-flops on the program/memory cards when system power is turned on or interrupted. Resetting is accomplished by using the power keyswitch, and allows clearing the flip-flops that store which detonators have been fired. This circuit uses a zener diode and transistors to detect the loss of power and reset the flip-flops.

d. Lamp Drivers. The lamp drivers switch on the power to illuminate the indicator lamps on the front panel. 
f. Constant-Current and Protection Circuits. These circuits regulate arm and trigger current to a fixed value and protect. against accidental overload. Each current regulator circuit uses 1/4 of a LM324 quad-operational amplifier chip, two optical couplers, and various discrete components to form a feedback network that controls the regulating. The overload protection circuit uses two of the remaining quarters of the LM324 to check for short circuits and to shut down arming in case of a short.

g. Logic Circuitry. This circuitry insures proper uphole control unit operation by monitoring the front panel switches and various circuits within the unit. It prevents selection or firing of more than one detonator at a time, refiring of an already fired channel, or improper sequence of operation, and it controls other functions important to proper operation. The logic circuitry consists of an array of $74 \mathrm{LS}-$ type logic gates (ANDS, NORS, NANDS, etc.) interconnected to perform the required functions.

IV. THE DOWNHOLE FIRING MODULE

The firing module (Fig. 4) is housed in a 3-in-diameter by 26-in.-long aluminum tube with Viton o-rings at each end to protect it from vibration and shock while the instrument package is lowered $\approx 10000 \mathrm{ft}$ into the borehole.

The firing module was fabricated from high-temperature components and polyimide printed circuit boards coated with Dow Corning

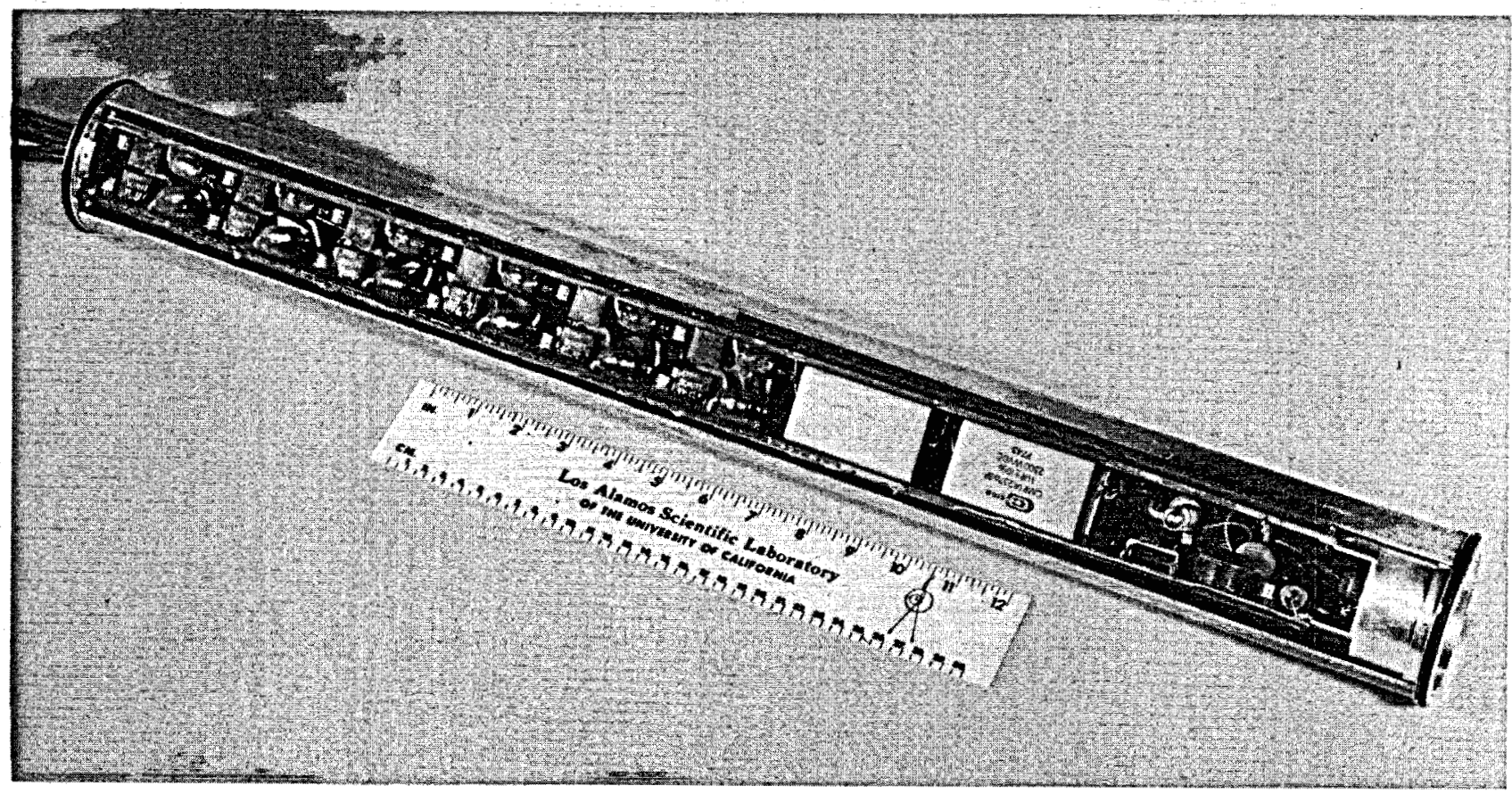

Fig. 4. The downhole firing module. 
3140 RTV for dielectric strength. The module will operate up to $150^{\circ} \mathrm{C}$ and will not be damaged by long-term exposure (24 hours) to $200^{\circ} \mathrm{C}$.

A dewar (Fig. 5) and pressure vessel (Fig. 6) are used to protect the firing module downhole. The dewar heat sink assembly, which included a 15-W heater in the electronic compartment, was lowered to $9800 \mathrm{ft}$, where there was an approximate temperature of $195^{\circ} \mathrm{C}$ for 24 hours. The temperature inside the dewar rose to $83^{\circ} \mathrm{C}$ at the end of the cycle. Because the inverter is turned on only momentarily $(\simeq 10 \mathrm{~s})$. for each detonator fired, the firing module does not contribute to the temperature rise in the dewar. Therefore, the downhole test was an overtest and this unit should function reliably beyond 24 hours.

Power requirements downhole are $\approx 20-\mathrm{V}$ dc, $300 \mathrm{~mA}$ to power the inverter, and a $50-\mathrm{V}$ pulse of $\approx 8-\mathrm{ms}$ duration to trigger each of the 12 channels. Power is supplied from the uphole control unit. Input voltages uphole depend on cable length, temperature, and cable resistance to ground. The logging cable now in use has seven conductors, is $25000 \mathrm{ft}$ long, and has a resistance of $250 \Omega$ and a minimum resistance of $1 \mathrm{M} \Omega$ to ground.

Operation of the downhole firing module requires a six-conductor cable. These conductors are used for $a+20-v$ dc input, ground, and selection of the desired channel. An additional conductor may be used to monitor either a vertical geophone or a voltage divider in the hv circuit to provide the surface recording instruments with a zero time and verify that the detonator has fired.

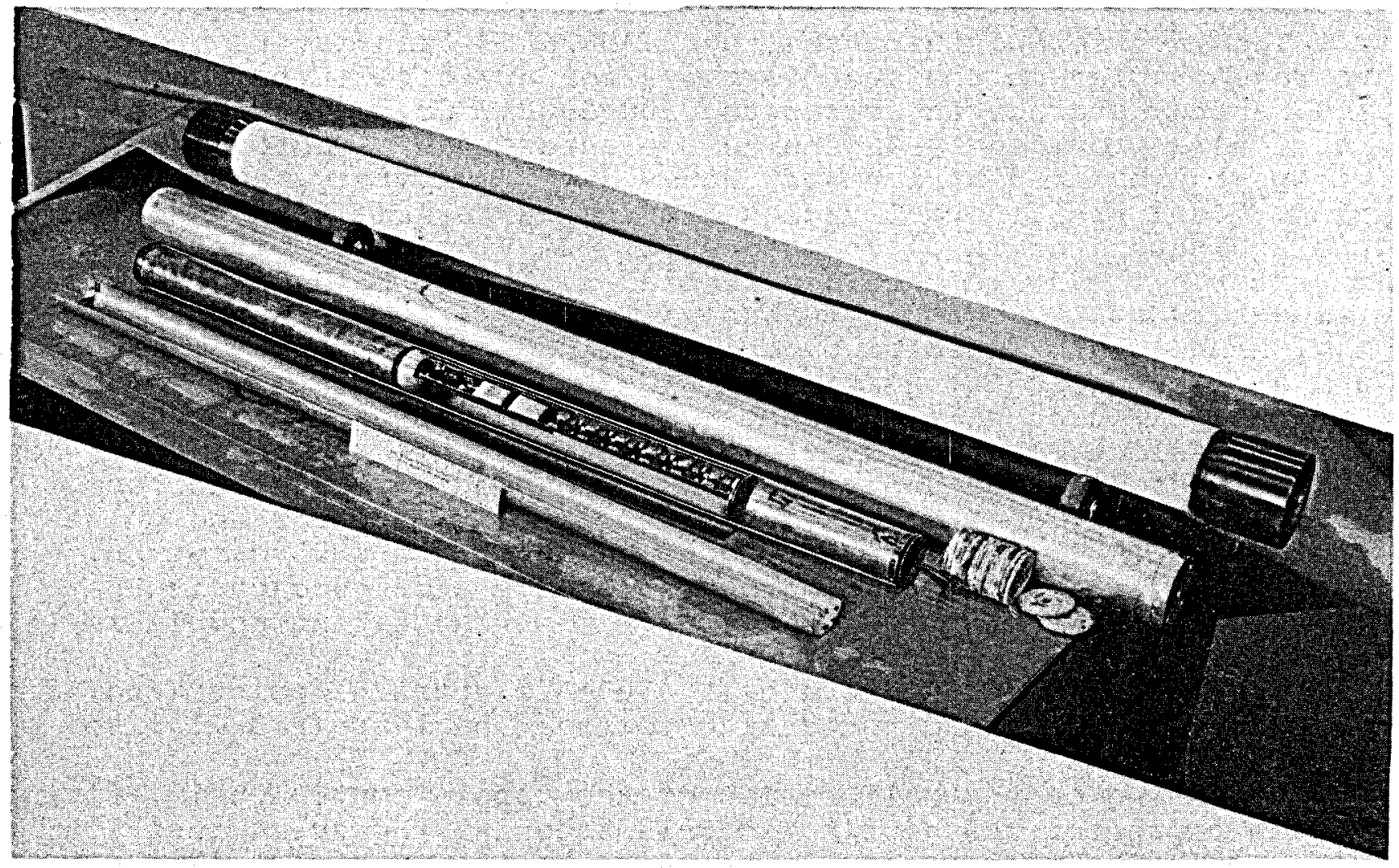

Fig. 5. The dewar assembly with firing module. 


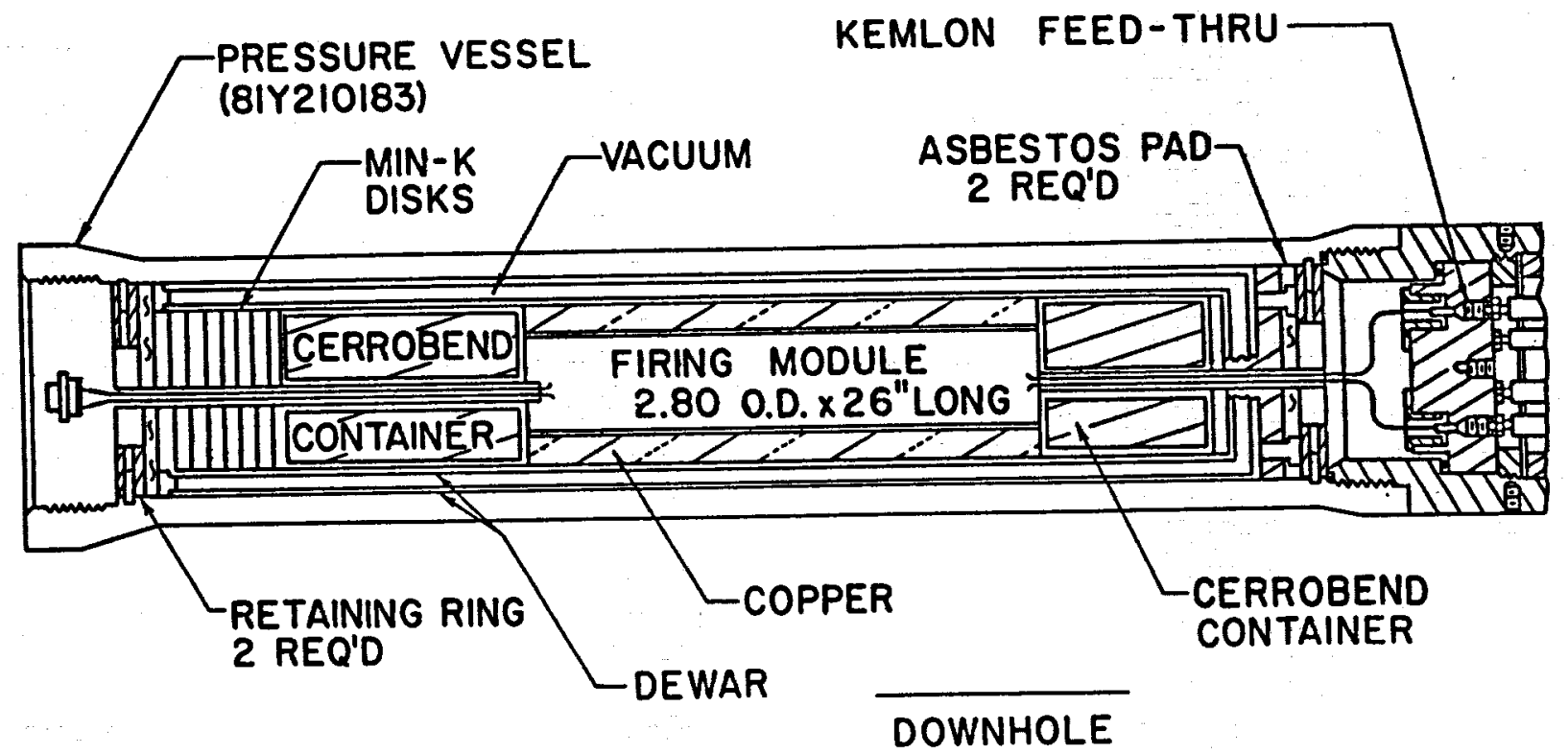

Fig. 6. Controlled environment enclosure (dewar) for downhole firing module.

The inverter circuit uses four JAN 2N657 transistors and a voltage tripler in the transformer secondary circuit to charge a $1-\mu F$ energy storage capacitor to $4500-5000-v$ dc. Overvoltage protection is provided by a zener diode across the capacitors that clamps the $\mathrm{hv}$ to a maximum of $5000-\mathrm{v}$ dc. For safety, an ITT Jennings Model RF-5, normally-closed hv relay insures that the energy storage capacitor is discharged until $+20-\mathrm{V}$ dc is supplied to the inverter. The hv is then distributed to the 12 EG\&G KN25 sprytron trigger tubes through the hv buss.

Channels are selected by using a diode matrix of a 48-V zener and a silicon diode in series with each TO-5 SPDT trigger relay. The trigger pulse polarity and proper selection of two of the fourchannel select conductors determines the channel to be fired. When the trigger relay is energized, it discharges a $6-\mu \mathrm{F}$ capacitor charged to $20-\mathrm{V}$ dc through a 2 N5339 trigger transistor and pulse transformer. This provides a $100-\mathrm{V}$ pulse to the KN25 sprytron, causing it to fire and discharge the energy storage capacitor through the detonator. A block diagram of the firing module is shown in Fig. 7.

The firing module generates a 4300-A electrical pulse (Fig. 8) with a $4500-v$ dc capacitor charge voltage and $1-\mu s(\approx 10-J)$ rise time.

Depending on the calibration of the uphole control unit, firing module capacitor charge time is 5-13 seconds. However, function time is in the microsecond range when the trigger pulse is delivered. 


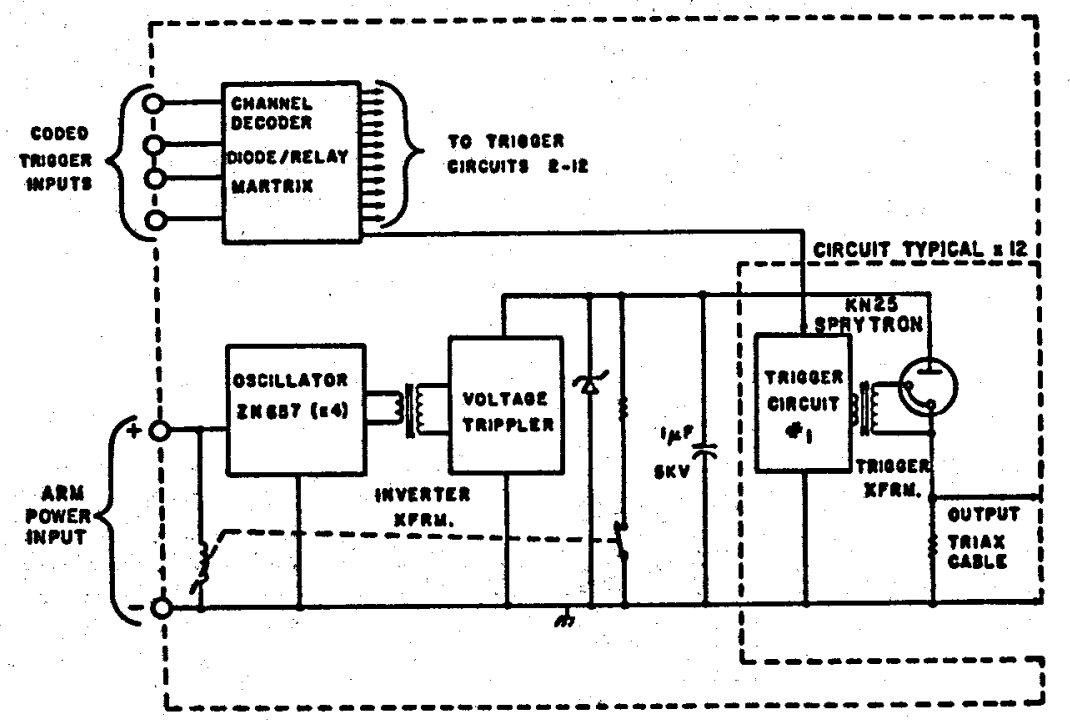

Fig. 7. The downhole firing module.

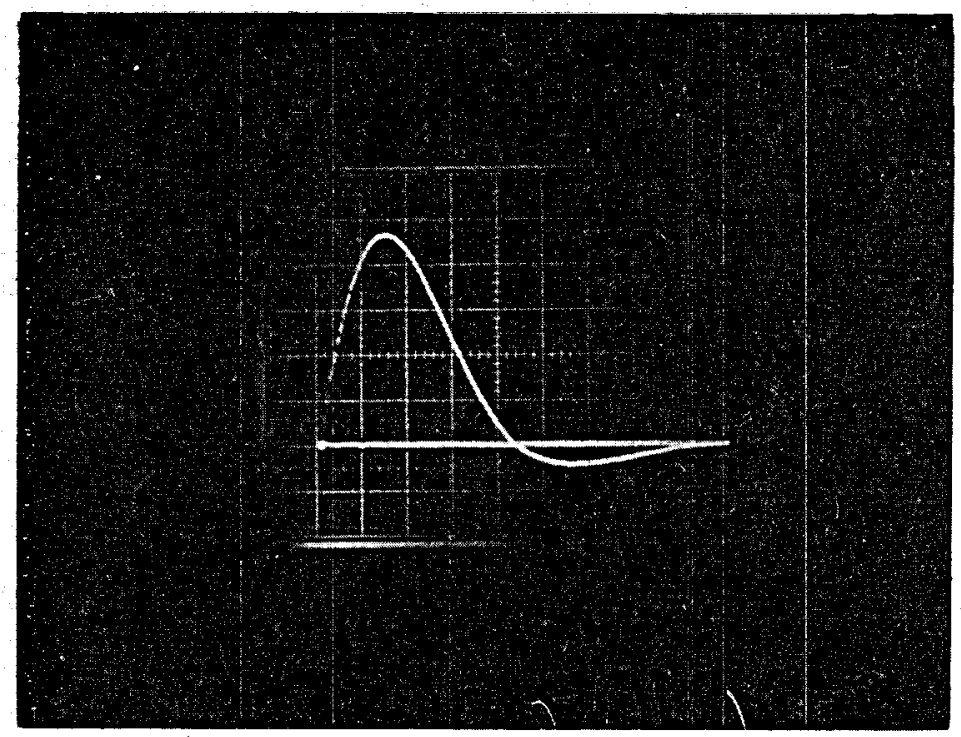

Fig. 8. Electrical pulse from firing module. 
To reduce system inductance and minimize the output current rise time required for dependable initiation of EFI detonators, a special triaxial output cable was made of standard " $L$ ". cable with a 5/16-in. copper braid pulled over it. Viton heat-shrink tubing secures the braid to the $\mathrm{I}$ cable. The cable was tested to a hv potential of $10-\mathrm{kV}$ dc to insure reliability.

\section{v. THE DETONATOR RACK}

The detonator rack is $3 \mathrm{ft}$ long and $6 \mathrm{in}$. in diameter with three levels, each divided into four compartments (Fig. 9). It is made entirely of stainless steel, except for the aluminum nose cone, and it will accommodate 12 detonators, each secured by a stainless steel clamp.

The electrical connection between the detonators and the highpressure bulkhead is made using the triaxial cable described earlier with Kemlon coaxial, high-temperature and -pressure boots, and feed-throughs. The cables are run through tubes in areas exposed to shrapnel from other detonators. The fact that the cables are reusable substantially reduces system cost and turn-around time.

\section{THE HIGH-TEMPERATURE DETONATOR}

The detonator (Fig. 10) is a separate sealed unit that contains only HNS explosive. This relatively insensitive secondary explosive provides maximum safety from accidental detonation, as well as

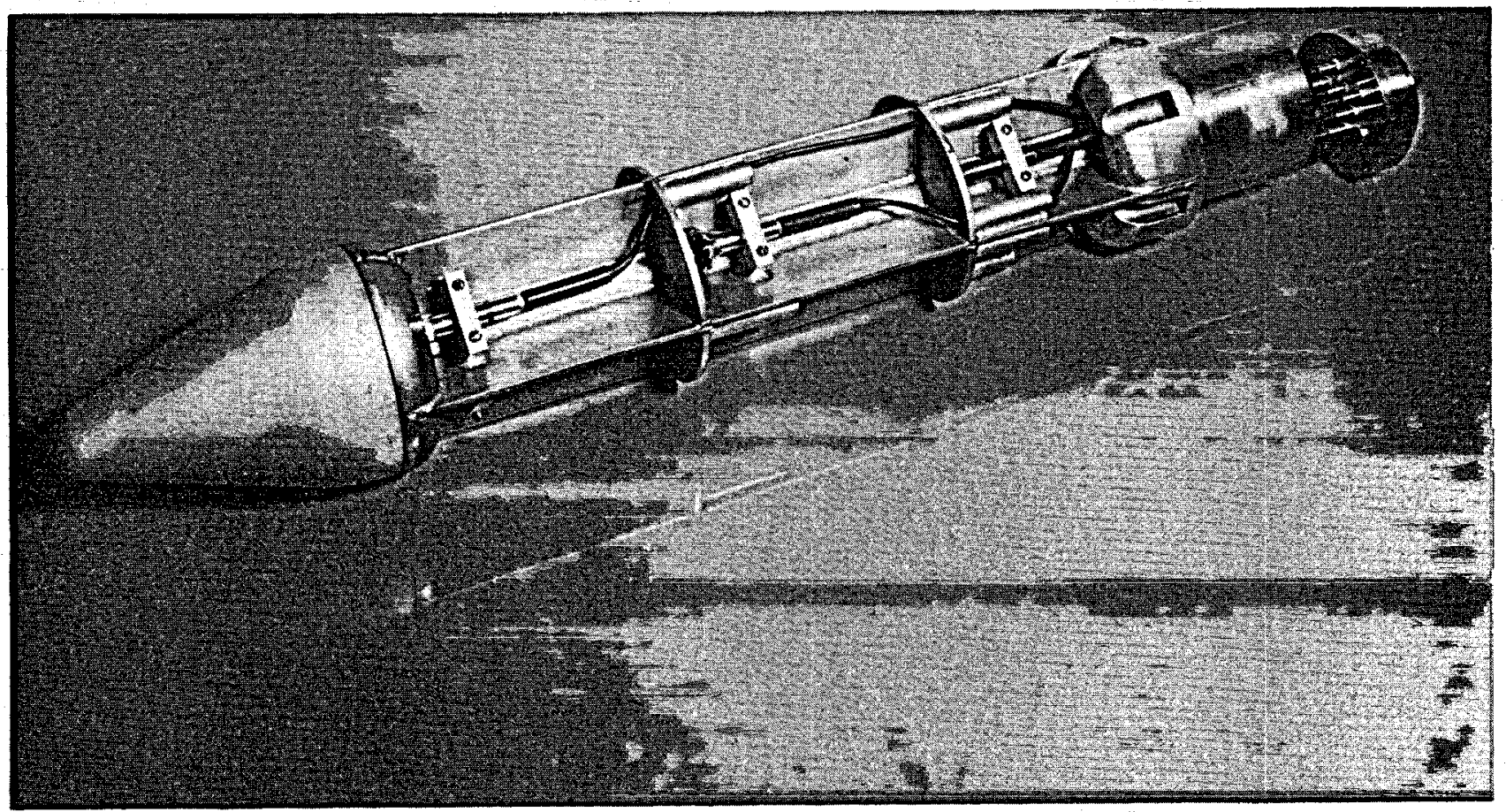

Fig. 9. The downhole detonator rack. 


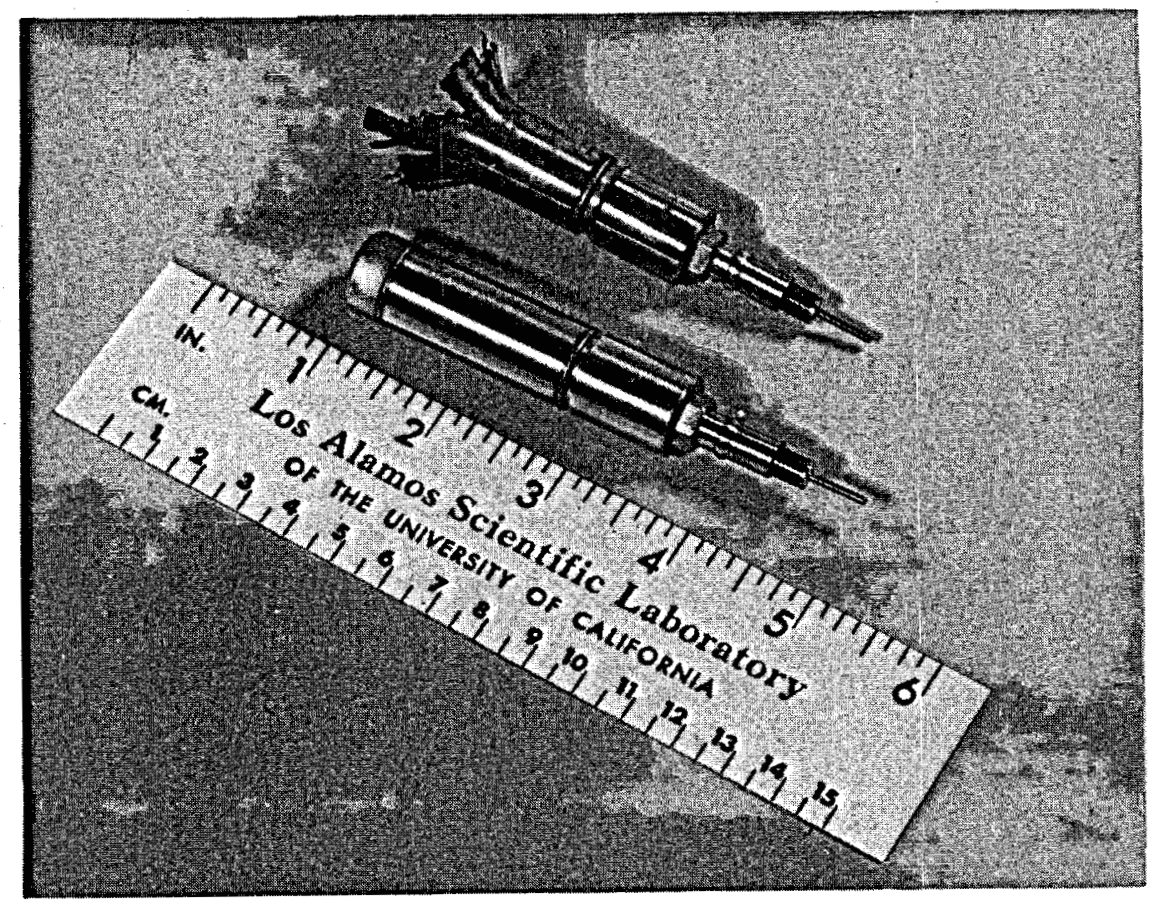

Fig. 10. The detonator before and after firing.

the required stability in a high-temperature environment. The detonator is a slapper initiator that contains $\approx 1 \mathrm{~g}$ of explosive. The high-current, high-power electrical energy pulse from the downhole firing module vaporizes a foil that accelerates a flyer which in turn strikes the explosive. The impact energy causes instantaneous detonation (within $1 \mu s$ ) of the explosive. The explosive is pressed to near-crystal density and is completely separated from all conductive parts. This enhances the detonator's safety characteristics and improves its long-term stability.

The detonator is housed in a welded stainless steel housing with a Kemlon high-pressure feed-through (16B-839) used to connect the hv coaxial cable. Figure 11 gives the dimensions of a typical HNS detonator.

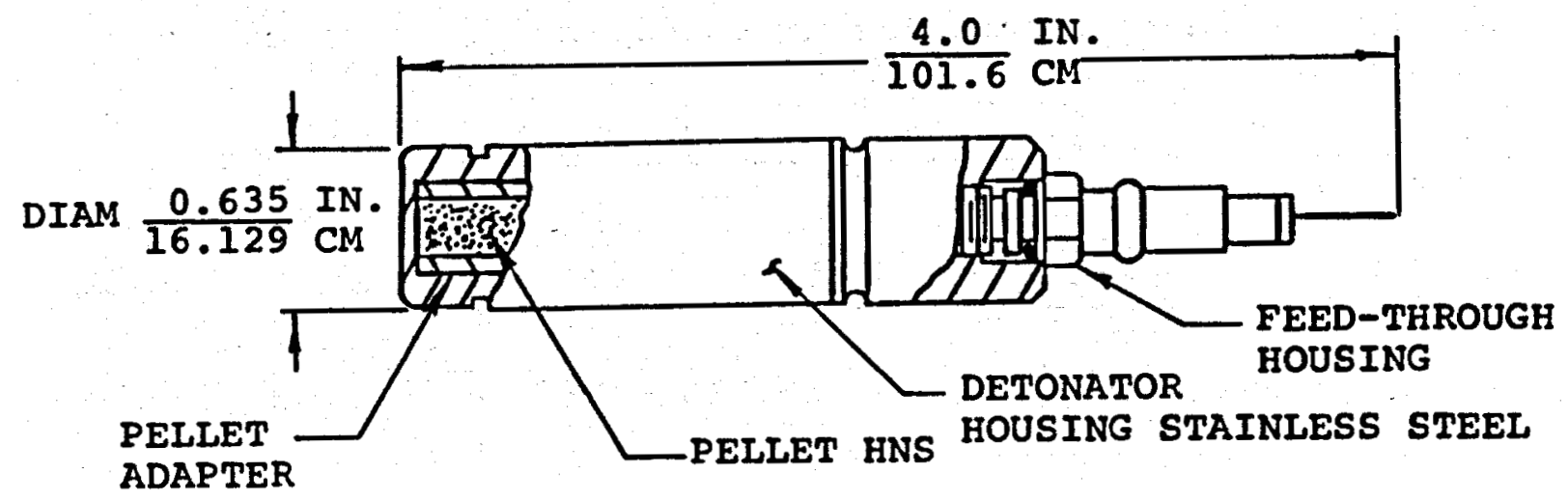

Fig. 11. Dimensions of a high-pressure HNS detonator. 
VII. DETONATOR SPECIFICATIONS

A. Performance

Threshold burst $\left(I_{b t h}\right) \ldots \ldots \ldots \ldots \ldots \ldots \ldots \ldots \ldots \ldots \ldots \ldots \ldots \ldots 2200$ A

$I_{\text {bth }}$ standard deviation....................... 120 A

All-fire burst current.......................

NOTE: These current levels are relatively high compared with Reynolds EBW Detonators; however, if the firing system (capacitor, trigger switch, cable, and connectors) is designed for minimum inductance and resistance and properly matched to the slapper initiation, total required energy is not significantly greater than a standard EBW system. For example, a reliable slapper initiation system can be designed and built with a 1- $\mu \mathrm{F}$ capacitor, charged to $4500 \mathrm{~V}$.

B. General

This initiator shall not function or degrade as a result of the following tests.

(a) $200^{\circ} \mathrm{C}$ for 4 hours.

(b) Dielectric withstanding voltage 500, 1-mA leakage per MIL-1-23659 C.

(c) Static discharge test, $25000 \mathrm{~V}$ with 500-pfd capacitor and a 500- $\Omega$ resistor per MIL-1-23659 C.

(d) For $\mathrm{P} / \mathrm{N}$ 167-8999, 5000-psi static pressure continuous.

(e) 28-V dc applied to the foil for at least 1 as specified in MIL-1-23659 C.

(f) Max no-fire test, $500-\mathrm{V}$ dc for $50 \mathrm{~ms}$ across the foil per MIL-1-23659 C.

(g) Explosive function time from foil burst to shock output shall be 4.0 us.

(h) Output characteristics: similar to RP-1 EBW detonator (P/N 167-4314).

This initiator shall not function (detonate), but may degrade, deflagrate, or dud as a result of the following tests.

(a) ac current test: 115-v ac, 60 cycles connected directly across the foil for $30 \mathrm{~s}$.

(b) Continuous temperature $200^{\circ} \mathrm{C}$. 